\title{
Bases epidemiológicas do Fator Acidentário Previdenciário*
}

\section{Epidemiological foundations of the Accident Insurance Factor}

\section{Vilma Sousa Santana' \\ 'Programa Integrado em Saúde Ambiental e do Trabalhador, PISAT, Instituto de Saúde Coletiva, Universidade Federal da Bahia}

*Versão preliminar publicada na Revista Conjuntura Social do Ministério da Previdência Social, 2004;(03):12-23.

Financiamento: Ministério da Previdência Social, Diretoria de Regime Geral.

Correspondência: Departamento de Saúde Coletiva, Instituto de Saúde Coletiva, UFBA, Campus Universitário do Canela, Rua Augusto Vianna, s/n $2^{\circ}$ andar, Salvador, Bahia, Brasil,401 10-040. E-mail: vilma@ufba.br

\section{Resumo}

Antecedentes: O Conselho Nacional de Previdência Social, por meio da Resolução No. 1.236 de 28/4/2004, aprovou uma nova metodologia para definição do valor das alíquotas de contribuição devidas por empresas para o financiamento de benefícios previdenciários relacionados aos riscos do trabalho. Esta metodologia baseia-se em um indicador denominado de Fator Acidentário Previdenciário, FAP, construído a partir do risco epidemiológico, estimado para cada ramo de atividade econômica. Como parte da sua estratégia de validação, o Ministério da Previdência Social decidiu pela avaliação da sua consistência epidemiológica. Objetivos: Nesse estudo analisaram-se os propósitos, as fontes de informação, a natureza das medidas epidemiológicas empregadas e a metodologia da construção desse indicador, identificandose as suas vantagens e limitações, aplicabilidade e impactos potenciais futuros. Métodos: Análise documental da Resolução No. 1236 e do documento anexo. Resultados: O FAP avança ao se pautar por critérios científicos transparentes que poderão permitir a redução das alíquotas quando houver efetiva melhoria das condições de trabalho, e conseqüentemente, da morbimortalidade entre trabalhadores. Supera as dificuldades relacionadas à definição e registro do nexo causal das doenças do trabalho ao considerá-las em sua totalidade, não se restringido às ocupacionais. Como prevê a redução de alíquotas com a melhoria das condições de saúde dos trabalhadores poderá contribuir para uma mais efetiva atuação dos empregadores na prevenção. Conclusões: É necessário o acompanhamento contínuo e sistemático da aplicação do FAP, com ampla participação da sociedade, revisando-o e ajustandoo aos diferentes cenários econômicos, sociais e de saúde do País, atentando-se para o seu impacto sobre a arrecadação e contas da Previdência Social.

Palavras-chave: Fator Acidentário Previdenciário. Alíquotas de contribuição. Seguro acidentes de trabalho. Seguridade social. Seguridade ocupacional 


\section{Abstract}

Background: The Brazilian National Social Insurance Counsel of the Ministry of Social Insurance approved the Resolution N. 1.236 of $28 / 4 / 2004$ that defines a new methodology to assess the value of taxes to be paid by firms, for occupational health related insurance costs. This methodology utilizes the Accident Insurance Factor, (Fator Acidentário Previdenciário) FAP, based on relative risks estimated for each industry trade. As part of its validation strategy, the Social Insurance Ministry decided to evaluate the epidemiological consistency of FAP. Objectives: The FAP purposes, data sources, the nature of the overall methodology, its advantages and limitations are all discussed, as well as its applicability and potential future impact on the Social Insurance Ministry budget and on the workers' health and safety. Methods: A documental analysis was conducted with the Resolution text and its attached essay. Results: The FAP represents an advance because of its transparent scientific criteria that may allows reduction of taxes, when improvement in work conditions and the resulting decrease in diseases or injuries are observed. It also overcomes problems of definition and assessment of occupational causal relationships because overall diseases and injuries will be considered regardless of their causal relation to occupational exposures. Since taxes can be reduced as work and health conditions improve, it may contribute to a more effective participation of employers in prevention. Conclusions: It is necessary to systematically and continuously monitor the application of FAP, with extensive society participation, reviewing and adjusting it to the distinct economic, social and health scenarios in the country, considering its impact on the Social Insurance budget.

Keywords: Accident Insurance Factor. Occupational taxes. Occupational injuries. Occupational disease. Occupational insurance. Social insurance.

\section{Introdução}

O objetivo da Resolução 1236 de 28/04/ 2004, do Conselho Nacional de Previdência, Ministério da Previdência Social, parte da "necessidade de se conferir estímulo ao desenvolvimento econômico, via redução de custos e fomento ao trabalho saudável, e o aperfeiçoamento do enquadramento dos ramos de atividade econômica por grau de risco, para fins de incidência de contribuição previdenciária", ao apresentar uma nova metodologia para o cálculo das alíquotas de contribuição de empresas para o pagamento de benefícios relativos a aposentadoria especial e agravos ocupacionais ${ }^{1}$. Esta metodologia é baseada no Fator Acidentário Previdenciário, FAP, um indicador global da carga epidemiológica estimada para cada ramo de atividade econômica, cujas bases conceituais e metodologia adotadas são mostradas em documento anexo.

Como parte da estratégia de validação do FAP, o Ministério da Previdência Social solicitou a alguns pesquisadores que avaliassem a sua consistência metodológica e em especial a epidemiológica, a partir dos documentos que compõem a Resolução. Nesse estudo, apresentam-se os resultados e recomendações decorrentes da análise, do ponto de vista epidemiológico, dos propósitos, fontes de informação, a natureza das medidas epidemiológicas empregadas, e a metodologia da construção desse indicador, identificando-se as suas vantagens e limitações bem como a sua aplicabilidade e impactos potenciais futuros.

\section{Sobre o propósito do FAP}

A seguridade social no Brasil foi contemplada na Constituição de 1988, sendo entendida como a garantia do direito à saúde, assistência e previdência social. No âmbito da Previdência Social, a seguridade compreende o reconhecimento e concessão de direitos aos segurados sob a forma, entre outras, de diversos benefícios classificados como previdenciários ou acidentários. Os 
benefícios acidentários relacionam-se à ocorrência de acidentes do trabalho, típicos ou de trajeto, e a doenças causadas ou relacionadas ao exercício de atividades laborais, AT/DT. Isto se encontra em conformidade com a Constituição Federal de 1988, que garante aos trabalhadores o seguro de acidentes do trabalho, a cargo do empregador (Inciso XXVIII do Art. No. 70), para os que têm vinculação empregatícia, consolidando o domínio da esfera pública sobre esta atuação, já prevista na Lei No. 5.316 de 1967.

A lógica subjacente ao propósito da Previdência Social é, portanto, compensar o trabalhador e seus familiares ou dependentes pelos danos resultantes dos agravos e doenças, incluindo-se aqueles causados pelo ambiente de trabalho inseguro. Como os danos são produzidos em locais e situações sob a responsabilidade do empregador, é óbvio que este deva contribuir para o custeio dessas despesas, e que o montante de sua contribuição seja função direta dos custos produzidos pelos agravos ocorridos ou que potencialmente venham a ocorrer. Este parece ser um dos princípios adotados para a definição do grau de risco de setores da atividade econômica e, conseqüentemente, da alíquota da contribuição e do montante correspondente devido pelos empregadores à Previdência Social no Brasil, até a vigência da nova Resolução 1.236 mencionada. Todavia, uma revisão sobre normas relativas a acidentes de trabalho no País não permitiu encontrar informações a respeito das bases científicas empregadas para a definição dos graus de risco das empresas da classificação vigente empregada pelo Ministério do Trabalho ou da Previdência Social. Riscos e custos parecem, portanto, ser elementos fundamentais para se compreender as bases da proposta do FAP.

Em epidemiologia, o risco é definido como a probabilidade de se tornar um caso, ou seja, de vir a ser enfermo, ou qualquer outro desfecho de interesse do investigador, que pode ser até mesmo a exposição, uma variação do estado de suscepti- bilidade, um acidente ou uma doença crônica ou aguda ${ }^{2}$. Note que como se trata de uma mudança de estado, de ausência para o de presença do fenômeno de interesse, isto envolve uma observação durante um certo tempo de um conjunto de indivíduos com chance de mudar este "estado". Comumente essa mudança é medida por uma probabilidade chamada de risco, incidência cumulativa, ou proporção de incidência ${ }^{3}$, e é definida com um referencial de tempo, geralmente a unidade de observação temporal como um ano, um mês, etc. Ora, quanto maior o risco, maior o número de casos novos relativos à população em risco de desenvolver o desfecho e, conseqüentemente, os custos envolvidos, na unidade de tempo. Vale ressaltar que a prevalência, medida de freqüência de casos novos e antigos, pode se constituir em uma medida ainda mais adequada por considerar os casos antigos que permaneceram com a enfermidade ou suas seqüelas. Denominam-se também de riscos, mas de modo inapropriado do ponto de vista epidemiológico, as exposições ou situações que se caracterizam por um aumento do risco de adoecer ou de se acidentar em relação a outras situações. Em epidemiologia, estas exposições que expressam um risco "relativo" elevado de adoecimento são chamadas de fator de risco, e envolvem, entre outras, a medida de risco relativo, ou razão de incidência cumulativa, comparando-se a incidência cumulativa entre os expostos ao fator de exposição em relação a esta mesma medida, estimada entre os não expostos. Um outro conceito importante é o de grupo de risco, que representa uma população com o fator de risco considerado, e que, embora possa apresentar distinções entre seus diversos integrantes, é considerado, para propósitos epidemiológicos, como homogêneo em relação à exposição identificada como fator de risco ${ }^{3}$.

Todavia, os custos são medida muito mais complexa do que o risco epidemiológico, e ainda se ressentem de poucos estudos, especialmente em países em desen- 
volvimento. Para começar, custos envolvem complexos aspectos políticos, culturais, e também da própria característica da ocorrência dos agravos, muitos deles de difícil mensuração. Envolvem também custos não mensuráveis, como o impacto emocional das perdas, por exemplo, quando existe a morte. Ademais, para muitos determinantes dos custos não estão disponíveis dados coletados sistematicamente, como existe para a doença, os acidentes ou as incapacidades. Por outro lado, os custos não são apenas imediatos e circunscritos, mas podem se prolongar por toda a vida do trabalhador, nas situações que requerem tratamento continuado, ou pensão devido a incapacidade permanente. Assim, embora os custos sejam função dos riscos de adoecer, são determinados por outros importantes componentes ${ }^{4}$. Um construto teórico, recentemente desenvolvido para dar conta dos impactos sociais e econômicos em saúde pública, é o de carga da doença, ou carga global da doença ${ }^{5}$, que leva em consideração outros aspectos além do risco epidemiológico, tratado em detalhe no artigo desenvolvido por Fassa et al. ${ }^{6}$.

O FAP propõe-se a avançar em relação aos critérios anteriormente empregados para a definição de graus de risco das atividades econômicas, ao apresentar bases para a definição das alíquotas, tomando como referência, além da medida de risco, indicada pela freqüência, a gravidade e os custos com o financiamento dos benefícios. Conforme apresentado, custos compensatórios de AT/DT estão associados à freqüência da ocorrência desses eventos, em especial ao risco. Portanto, este novo indicador constitui um avanço ao adotar um critério baseado na extensão do problema, ainda que não considere a carga global da doença/acidente, strictu senso. Os custos são dependentes também da gravidade do problema, nesse caso específico, medido com um indicador baseado na duração relativa do benefício. Com esta medida, o FAP contempla a duração dos efeitos, especialmente quando se consideram as incapaci- dades ou o caráter crônico, remitente ou recidivante de muitas enfermidades comuns. Por último, incluem-se as despesas relativas ao pagamento dos benefícios, que se presume constituir parte substantiva do total de dispêndios relacionados com os AT/DT. Portanto, é inegável o avanço do FAP em relação aos critérios adotados anteriormente, em especial em relação às dimensões quantitativas mensuráveis empregadas para definir o montante da alíquota. Vale ressaltar que, além de uma especificação e detalhamento dos seus critérios, o FAP se assenta em bases científicas, sejam da epidemiologia, consagrada como um dos pilares da saúde pública, e também da economia e estatística.

No bojo geral da proposta, cabe assinalar que a sua lógica, embora apresentada com um propósito geral de uma mera racionalidade de custos, pode ter conseqüências muito positivas no sentido da prevenção dos $\mathrm{AT} / \mathrm{DT}$. Isto porque, de acordo com Dorman ${ }^{4}$, um dos principais fatores determinantes da adoção de medidas de prevenção de agravos e doenças do trabalho, por parte de empresários, é a bonificação das iniciativas, em especial quando estas levam à redução dos acidentes e, conseqüentemente, dos custos para a empresa. Todavia, mesmo em países industrializados, o interesse e a quantificação dos custos decorrentes de acidentes de trabalho praticamente inexistem, limitando, portanto, o incentivo à prevenção pela redução de despesas, para as quais não há disponibilidade de informações. Nessa perspectiva, é bastante promissora a possibilidade de, com a aplicação do FAP, algumas empresas virem a reduzir sua alíquota de contribuição. Ou seja, se efetivamente forem reduzidas as ocorrências de enfermidades e acidentes por meio de ações preventivas ou de promoção da saúde, a empresa poderá pagar menos. Entretanto, deve se considerar que, com base em diversas pesquisas realizadas em diferentes contextos no País, pôde-se constatar que é muito comum o sub-registro nos documentos da Previdência, como a CAT, prontuários e outros do- 
cumentos de registro de saúde. Isto é causado por vários fatores, principalmente econômicos, e interesses patronais, que assim evitam a visibilidade desse aspecto negativo de suas empresas. Sub-registros são de responsabilidade de vários atores sociais, em especial os empregadores, e também profissionais de saúde, preocupados com possíveis implicações legais, e até mesmo os próprios trabalhadores que assim evitam o estigma e a exclusão de oportunidades de trabalho, de que muitas vezes são alvo após a ocorrência deste tipo de evento ${ }^{7-10}$. Estudos específicos devem ser urgentemente realizados, de modo a fundamentar propostas apropriadas para a redução do sub-registro dos acidentes e doenças ocupacionais que deverão ser prontamente adotadas.

\section{Sobre as fontes de dados}

Como o propósito do FAP é a obtenção de informações sobre a carga das enfermidades relativas ao ramo de atividade econômica de empresas, ao longo do tempo e em âmbito nacional, é necessário que os dados respectivos provenham de todo o território do País, de todas as empresas que componham a população de trabalhadores elegível para os benefícios, de modo contínuo e abrangente. Como as fontes de dados a serem empregadas são de abrangência nacional, de registro e coleta contínuos e sistemáticos ao longo do tempo, e disponíveis para as instituições de interesse isto lhes confere, por si só, a devida justificativa para a incorporação na criação e cálculo do FAP. Há que se considerar que o objetivo é administrativo e não de investigação, e que os dados são inerentemente administrativos, sejam os denominadores ou os numeradores. É sabido que dados administrativos relativos à saúde são de melhor qualidade quando se destinam especificamente aos propósitos para os quais foram gerados ${ }^{11}$. Assim, se o objetivo é o cálculo de parâmetros relativos aos benefícios, os dados serão melhores quando forem utilizados para se obter essas informações.
Entretanto, um obstáculo ao uso dos dados relativos aos benefícios é o fato de refletirem uma resposta à uma demanda do trabalhador e, portanto, serem função da disponibilidade e do acesso, do conhecimento do trabalhador, e em especial do seu desejo e determinação em buscar e obter o benefício. Em relação aos dados dos trabalhadores em risco obtidos de registros das empresas, para fins de cálculos de pagamento de taxas previdenciárias, é possível que estas estejam também sujeitas à sub-registro, mesmo para os trabalhadores efetivamente portadores de contratos formais de trabalho.

Em estudo prévio com parte da base de dados em causa, estimou-se que, embora o diagnóstico de saúde classificado pela CID fosse pequeno, a falta de informação sobre o ramo de atividade da empresa na qual o trabalho exercia suas atividades, o CNAE, não era registrado em cerca de um terço dos benefícios ${ }^{12}$. Vale assinalar, portanto, a importância de que estes registros sejam melhorados tanto para a aplicação e o aprimoramento do FAP quanto em relação ao grande valor das estatísticas previdenciárias para o País, e em especial à possibilidade do seu uso para os mais variados estudos epidemiológicos. Esperase que o FAP seja acompanhado de medidas rigorosas visando a melhoria da qualidade de registro das bases de dados que o compõem, em especial da CNAE, e do diagnóstico clinico nos documentos relacionados com os benefícios previdenciários. Como já foi assinalado, medidas para a superação desse importante problema deverão ser traçadas e implementadas.

\section{Sobre o uso da razão de chances}

De acordo com o documento anexo à Resolução No. 1.236, a seleção das unidades de análise empregadas para identificar os grupos de risco será realizada de acordo com uma medida epidemiológica: o excesso de "risco". Para entender esta medida deve-se considerar que o risco relativo, fundamental para se identificar fa- 
tores de risco e os grupos de risco, é uma estimativa baseada em razões de proporções. Ora, quando não existe diferença entre as proporções ou os riscos entre expostos (Re) e não expostos ao fator (Rne), o risco relativo, que é uma razão (Risco Relativo $=$ Re / Rne), será igual a 1,0. Ao contrário, quando houver maior risco entre os expostos em comparação ao não expostos, o risco relativo é maior que 1,0 . Por exemplo, se o risco de acidentes não fatais de trabalho entre trabalhadores da construção civil for de $8,1 \%$ por ano, enquanto a estimativa foi de $5,4 \%$ ao ano entre os demais trabalhadores, o risco relativo será de 1,5 ( $R R=8,1 / 5,4=1,5)$, o que representa um excesso de risco (Excesso de Risco $=1,0$ - Risco Relativo) de 0,5 ou de 50\%. Em outras palavras, um excesso de risco dessa magnitude revela que o risco entre os expostos é $50 \%$ maior do que entre os não expostos. O uso dessas medidas epidemiológicas para a construção do FAP é procedente, no sentido em que expressa um diferencial quantitativo de ocorrência de desfechos adversos, em referência a um condicionante, no caso a exposição. Vale notar que esta medida por si só não significa uma associação causal, que envolve o atendimento a outras condições, como os critérios de causalidade de Bradford Hill ${ }^{13}$.

No documento de referência, propõese que em vez de o risco relativo seja utilizada a razão de chances, mais conhecida pela sua denominação em inglês, a odds ratio. Apresenta-se no texto que "a razão de chances satisfaz plenamente os objetivos propostos, com vantagens diferenciadas de outras associações pelo fato de apresentar melhores propriedades estatísticas", indicando-se em uma nota de rodapé que a RC, ao contrário do risco relativo, ou razão de riscos, "trabalharia a possibilidade de sucesso e de fracasso" e por isso seria mais “incisiva”" . Estas afirmações merecem maior detalhamento e especificação, pois não se sustentam nos fundamentos teóricos, sejam epidemiológicos ou estatísticos, e no próprio contexto de aplicação ao problema em estudo.
Inicialmente, é importante assinalar por que os epidemiologistas usam a odds ratio. Esta é uma medida de associação desenvolvida para a análise de estudos caso-controle, nos quais a população de estudo foi selecionada diferencialmente para casos e não casos. Ou seja, em uma população de base de onde provém toda a população do estudo, identificam-se todos os casos, que constituem o grupo de casos, e dentre os não casos, seleciona-se uma fração ou amostra que irá, juntamente com os casos, compor o total da população de estudo. Este desenho de estudo, também chamado de fração amostral incompleta $^{14}$, constitui muitas vezes o único meio possível de se estudar a etiologia de enfermidades raras, consideradas como aquelas de ocorrência menor que $10 \%^{3}$. O estudo de desenho caso-controle, por tratar apenas de uma fração do grande número de não casos, permite a coleta de informações de modo eficiente e pouco custoso. Como nesses estudos a população é fracionada a priori, de acordo com a doença ou o desfecho de interesse, sua análise requer um tratamento diferenciado, o que foi brilhantemente desenvolvido por Cornfield (1955) ${ }^{15}$.

Esta análise baseia-se na razão de chances ou odds ratio, cujo fundamento, a odds, representa uma razão de proporções na qual o numerador é uma proporção e o denominador o seu complemen$\operatorname{tar}(1-p)$, ficando, portanto, odds=p / (1p). A análise do estudo caso controle parte da comparação entre a odds de ser exposto dada a condição de doente, e a odds de ser exposto dada a condição de não doente, que corresponde a uma razão de odds. Com um certo desenvolvimento algébrico chega-se à uma fórmula reduzida, na qual a razão é obtida dividindo-se o produto entre o número de casos expostos pelo número de não casos não expostos, pelo produto do número de casos não expostos vezes o número de casos expostos. As odds ratios equivalem à razão das taxas de incidência, e também ao risco relativo, se e somente se, certas condições sejam aten- 
didas. Uma delas é a raridade do desfecho e outra a estabilidade da freqüência da exposição, ou seja, quando for menor ou em torno de $10 \%$. Nessas condições, a odds ratio é uma boa aproximação estatística das medidas baseadas em razão de proporções, como o risco relativo ou a razão de prevalências, para casos incidentes e existentes ou prevalentes, respectivamente, entre outras. A odds ratio é a única medida de associação viável para análise dos estudos de caso-controle, porque os dados marginais das tabelas correspondentes não permitem o cômputo de proporções válidas, exceto quando se dispõe de alguns dados sobre a população, o que permite a sua derivação. Outros pressupostos não serão apresentados por serem considerados desnecessários neste contexto. A questão levantada nesta situação específica é: será possível garantir a raridade dos eventos de interesse em todos os CNAE? Embora isso seja plausível, é necessário que este aspecto seja aventado nesta discussão, desde que as odds ratios superestimam o risco relativo quando a doença ou agravo de interesse não é raro, e ampliam a imprecisão estatística. Como há disponibilidade de dados para toda a população e a razão de proporções é de cálculo simples e de compreensão mais fácil, não se justifica o uso das odds ratios ${ }^{2,3}$.

Outro ponto a considerar é que com os dados preliminares apresentados no documento em causa, embora o alfa tenha sido definido em nível muito baixo, não é necessário trabalhar com intervalos de confiança ou inferência estatística, uma vez que se trata do universo populacional e não de uma amostra, além de não se tratar de teste de hipótese causal ${ }^{3}$, não se aplicando, portanto, testes estatísticos.

Além desses aspectos mais estatísticos, é necessário considerar a definição do grupo referente no qual se baseará a definição da medida de associação. Este é um aspecto crucial, pois a mudança de referente pode modificar completamente o resultado e, conseqüentemente, a alíquota, tornando necessária uma definição bas- tante clara, a priori, dos seus critérios. Isto significa que a medida será determinada, em grande extensão, pela categoria de empresas considerada como não exposta. Obviamente, como isso representa um fator importante na definição das alíquotas, haverá pressões das partes interessadas visando a manipulação do grupo/empresa referente escolhido.

\section{Sobre os critérios}

\section{Em relação à freqüência}

A utilização de dados na construção de instrumentos para a gestão devem se pautar, entre outros aspectos, na simplicidade, qualidade, cobertura e a permanência da sua disponibilidade ao longo do tempo, nas diversas instâncias administrativas. Portanto, os parâmetros são bastante diversos daqueles empregados em pesquisas, nas quais os dados são coletados para frações específicas da população, em um determinado período de tempo, ampliando-se em geral a sua quantidade e complexidade. Assim, para o FAP, instrumento administrativo e não de investigação, não se pode contar com uma grande variedade de dados, o que poderia comprometer sua viabilidade operacional. Isto certamente justifica, de modo substantivo, um de seus pressupostos, que é o da igualdade quantitativa dentre os desfechos considerados. Isto quer dizer que, ao se contabilizarem os diferentes benefícios conjuntamente, adicionando-se os valores correspondentes a enfermidades comuns, ocupacionais, e pensão por morte, por exemplo, cada um deles passa a representar uma mesma unidade de medida - o benefício - desconsiderando-se a diferença das causas que o originaram. Por exemplo, é reconhecido que um óbito tem um valor ou custo transcendente em relação à incapacidade temporária, e que esta, por sua vez, representa, uma experiência humana e também relativa à sua dimensão econômica, distinta em relação à incapacidade permanente. Todavia, a contabilização desses eventos em uma mesma me- 
dida é legítima, considerando a viabilidade do cálculo do indicador para fins administrativos.

Uma outra diferença fundamental entre desfechos, do ponto de vista epidemiológico, é o fato de serem incidentes, ou seja, caso novo surgido em um período de observação de um grupo de não casos, ou prevalentes, representando a soma de casos novos e existentes em um dado momento de tempo. Há que se notar que algumas enfermidades, por suas próprias características, são recidivantes, recorrentes ou remitentes, o que implica na ocorrência de diversos episódios ao longo do tempo. Todavia, do ponto de vista do propósito do FAP, estas características não representam uma heterogeneidade dos benefícios que possa comprometer a qualidade dos seus indicadores parciais e finais neste contexto.

Um outro aspecto a ser considerado, na discussão do uso do indicador baseado na freqüência global dos benefícios, é a eliminação da diferença fundamental entre doenças ou agravos ocupacionais e não ocupacionais, que se concretiza na computação agregada dos benefícios para a estimativa do risco relativo e do correspondente excesso de risco. Isto significa uma ruptura radical entre os critérios usualmente empregados de distinção entre doença ou agravo ocupacional, e os não ocupacionais. Esta mudança representa, por um lado, um aspecto positivo, ao se eliminar a necessidade do registro do nexo causal, alvo de rejeição ou negligência por parte dos profissionais de saúde responsáveis pelo diagnóstico clínico para fins de definição de alíquotas de contribuição. E, por outro lado, é também foco de grandes dificuldades na sua definição, especialmente devido à natureza multicausal de muitas enfermidades e agravos ocupacionais, bem como os aspectos jurídicos, administrativos e previdenciários relacionados à confirmação destes diagnósticos. É necessário deixar claro que a distinção entre a natureza ocupacional ou de saúde geral dos benefícios cumpre uma função pedagógica importante, ao "ensinar" e registrar oficialmente que existem problemas causados pelo modo como o trabalho se organiza socialmente e se concretiza nos processos e ambientes de trabalho. E que a existência de benefícios previdenciários relacionados às conseqüências do trabalho torna visível a morbidade e mortalidade ocupacional, ao permitir a quantificação e divulgação do quanto adoecem ou se lesionam os trabalhadores por fatores evitáveis, ocupacionais. Neste ponto é difícil prever as conseqüências que este “apagamento", ainda que restrito à quantificação de alíquotas, possa desencadear um processo mais amplo de unificação dos benefícios previdenciários, e o completo desaparecimento dessa distinção, fundamental para a saúde pública e para o bemestar futuro dos trabalhadores.

Com a utilização da categoria enfermidade em geral e não ocupacional para o cálculo das alíquotas de contribuição poder-se-á, no futuro, encontrar um motivo forte para a eliminação também da emissão da Comunicação de Acidentes de Trabalho, CAT. Ou mesmo da garantia de que, a partir da emissão da CAT, poderá se passar ao reconhecimento da natureza ocupacional do agravo, o que pode ser possível dentro do próprio sistema de atendimento previdenciário, muito embora persistam os benefícios acidentários tradicionais. Isto de fato já vem ocorrendo, pois em um estudo recente ${ }^{12}$ constatou-se, com dados da previdência, que $62 \%$ dos benefícios acidentários não contavam com o registro da CAT, enquanto entre acidentados do trabalho identificados em um estudo de base comunitária, na mesma área urbana, apenas 3\% dos trabalhadores acidentados com contrato formal referiram ter a CAT emitida ${ }^{9}$. São inúmeras e já bastante estudadas as razões para o sub-registro dos agravos e doenças ocupacionais no Brasil e no mundo, não cabendo neste documento a repetição desses achados. Apesar das limitações da CAT no momento, pensa-se que, ao contrário da sua eliminação, dever-se-ia considerar o seu aprimoramento e garantia para que, de 
fato, venha a representar um instrumento de qualidade para gerar informação sobre saúde do total de trabalhadores no Brasil, e não apenas para os informais.

Um outro aspecto a considerar é que isso pode ocasionar uma relativização ou redução do interesse no registro da natureza ocupacional dos AT/DT, uma das razões para o alarmante sub-registro observado em nosso País. Nesta perspectiva, poderá ocorrer uma drástica redução do número de registro desses eventos, comprometendo os recentes esforços empreendidos para a melhora da qualidade das estatísticas oficiais desses eventos. Há que se considerar que o nexo causal e a emissão da CAT são expressões do reconhecimento clínico epidemiológico, e são empregados como evidências no âmbito jurídico para questões relativas à indenizações, por exemplo, o que pode ter conseqüências negativas, a médio e longo prazo, para os interesses dos trabalhadores. Todavia, estas são apenas projeções futuras, visto não existirem evidências para o exame dessas possíveis conseqüências, mas que deverão ser objeto de avaliações específicas posteriormente.

Em resumo, um aspecto significativo do FAP e sua metodologia é que a consideração dos excessos das enfermidades em seu conjunto, e não apenas as ocupacionais ou relacionadas com o trabalho, pode pavimentar o caminho para uma concepção de saúde integral, base das ações voltadas para a promoção da saúde, superando-se a visão de que as práticas de saúde do trabalhador limitam-se à prevenção apenas das doenças e agravos estritamente ocupacionais. Como já foi assinalado, esta medida conforma várias implicações conceituais que podem vir a se traduzir, a médio e longo prazo, em um apagamento da importância da definição da natureza ocupacional de doenças e agravos, resultado de centenas de anos de pesquisa e também da luta dos trabalhadores.

\section{Sobre o indicador de freqüência}

É apresentado o “Coeficiente de Fre- qüência" definido como a razão entre o número total de benefícios especificados e o número médio de vínculos empregatícios. Sugere-se que em seu momento de avaliação o documento anexo à Resolução 1236 seja revisto em sua redação, contemplando com mais rigor a terminologia empregada na epidemiologia. Por exemplo, coeficiente expressa proporção, um tipo especial de razão, na qual o numerador está contido no denominador. Na epidemiologia clássica, os coeficientes para morbidade com base na proporção são a prevalência, quando se tratar da proporção de casos existentes ou prevalentes em uma dada população, em um tempo instantâneo. E a incidência proporcional, risco ou incidência cumulativa, que trata da proporção de novos casos em uma população de não casos, em risco de adoecer, acompanhada por um tempo determinado $^{2}$. Com base na fórmula apresentada e no texto que a acompanha, é necessário que se especifique que no numerador encontram-se os casos, ou seja, pessoas para as quais foram emitidos ou despachados benefícios especificados. E que o denominador é a população em risco de receber a concessão desses benefícios, medida pela média de vínculos empregatícios declarados pelas empresas, assumindo-se que cada vínculo corresponde a um trabalhador. Assim a denominação de coeficiente fica apropriada à formula apresentada e contempla a igualdade da natureza de ambos, numerador e denominador. Acredita-se que o uso da palavra proporção seja mais correto do que o utilizado - razão -, pelas considerações já apresentadas.

Caso os dados dos benefícios limitemse aos despachados, pode-se considerar os casos como incidentes, e a população de trabalhadores como "em seguimento", analogamente à um estudo longitudinal de vários registros ao longo do tempo na mesma população, com o registro de todos os casos ou "benefícios". Assumindo-se que os trabalhadores, ao entrarem na força de trabalho, estão livres das doenças ou agravos que os levaram a receber o benefício, 
posteriormente, e que o tempo de seguimento é conhecido, atende-se a todos os requisitos para a consideração de um estudo longitudinal (ou coorte). Assim, poder-se-ia considerar a medida proposta, sob estes pressupostos, uma medida de incidência cumulativa ou de risco, e o desenho de estudo longitudinal.

\section{Sobre a gravidade}

Um indicador tradicional de gravidade para uso no cálculo de indenizações é o que se baseia na natureza e no grau de incapacidade: fatal, permanente total, permanente parcial, temporário total e temporário parcial. Para fins de compensação ou indenização, todavia, pode-se recorrer a classificações relativas ao grau de impedimento funcional ou físico, ou perdas de ganhos futuros presumidos, desde que a depender do tipo de lesão haverá ou não comprometimento de ganhos potenciais em empregos futuros por parte do trabalhador ${ }^{16}$. Utiliza-se como medida de gravidade dos AT/DT, no FAP, a duração dos dias perdidos de trabalho, tradicional para a caracterização do tempo de incapacidade temporária e que se baseia nos ganhos perdidos. Para a incapacidade permanente é necessário empregar-se uma referência como a expectativa e anos potenciais vividos com a incapacidade. Embora não especificado, é presumível que um cálculo análogo seja utilizado para os B94, referentes às mortes.

Cabe aqui também uma discussão dos seus aspectos positivos e negativos. Como vantagem desse indicador, identifica-se a simplicidade e disponibilidade da informação. Entretanto, como também se encontra registrado o tipo de seqüela relativa às incapacidades permanentes ou temporárias, esta informação poderia ser empregada para uma classificação que se sustente em maior detalhamento e especificação das perdas do trabalhador, para além dos seus ganhos. Interessante lembrar que os dias perdidos de trabalho representam um custo indireto desses agravos, por afetar a pro- dutividade. Entretanto, para fins administrativos e com vistas à simplicidade do procedimento, considera-se plenamente aceitável a medida proposta, como aproximação da gravidade.

\section{Sobre a medida de gravidade}

Em relação à denominação, o termo coeficiente de gravidade é adequado, pois a análise da fórmula permite a compreensão de que o numerador expressa uma medida de tempo, os dias perdidos correspondentes aos trabalhadores que receberam benefício, enquanto o denominador corresponde ao somatório dos tempos médios estimados de cada trabalhador. Seria mais transparente explicitar a natureza da constante, que suponho expressar o número de dias por ano, mais um fator de correção de 0,25 para os anos bissextos. Uma outra questão refere-se à notação, que não se encontra homogeneamente disposta no texto, a exemplo do código do benefício que é utilizado na fórmula de Coeficiente de Freqüência como trabalhadores, e para o Coeficiente de Gravidade representando tempo em dias.

\section{Sobre os custos}

Os custos representam importante aspecto na definição da alíquota do FAP e, como anteriormente mencionado, perpassam todos os critérios empregados para a definição do fator em causa. Para Dorman", o interesse crescente da economia da saúde em relação aos agravos ocupacionais está assentado no modo como as informações econômicas podem contribuir para a prevenção, e como despesas com prevenção podem ser consideradas como investimentos, no nível empresarial. Diante de controvérsias entre diversos autores sobre quais seriam as melhores e mais adequadas medidas econômicas para a avaliação de custos, este autor propõe a discussão das seguintes relações: custos econômicos \& não econômicos, fixos \& variáveis, diretos \& indiretos, e internos \& externos, todas elas 
envolvidas na estimativa de medidas econômicas. Todavia, o que mais interessa aos empresários para o estabelecimento de programas de prevenção são os custos econômicos variáveis, diretos e internos. Como evidências empíricas têm demonstrado que os custos indiretos, externos às firmas, são mais elevados que os diretos, é de grande importância para as políticas de Estado, a estimativa dos custos indiretos ${ }^{17}$.

Os custos econômicos são aqueles para os quais é possível se utilizar uma medida econômica, ou seja, podem ser calculados. Compreendem os custos efetivamente pagos ou previstos de serem pagos, como também os valores monetários orçados ou previstos. O valor da vida, e conseqüentemente de uma vida perdida, é para muitos, incomensurável, e para o qual não é possível uma recompensa monetária. Portanto, não pode ser traduzida em uma medida monetária, embora seja, de longe, o mais importante impacto a ser considerado. Outros custos não econômicos, e portanto, não mensuráveis seriam os desconfortos físicos ou emocionais, que se tornam particularmente inaceitáveis quando resultam de situações de injustiça ou do não cumprimento de uma legislação existente. Para Dorman ${ }^{4}$, estes custos não econômicos seriam os "humanos".

É claramente difícil a incorporação de todos os aspectos que representam o custo social em uma única medida apenas, especialmente pelas características requeridas para o seu uso administrativo, sistemático, ao longo do tempo, como no FAP. Todavia, no próprio bojo da epidemiologia já se tornaram disponíveis medidas como a dos anos ajustados de vida com incapacidade (disability adjusted life years), mais comumente conhecido por DALY ${ }^{5}$. Esta medida incorpora outras dimensões que não apenas os custos, mas também a cronicidade, a incapacidade, a idade em que ocorre, entre outros aspectos constituindo um indicador global mais abrangente da carga da doença e dos acidentes. A incorporação desta medida no cálculo do FAP deverá ser considerada no futuro, desde que haja dis- ponibilidade de recursos computacionais e de dados com as características requeridas para seu uso administrativo.

\section{Sobre a criação dos agrupamentos de risco}

O texto de apresentação é extremamente sucinto, o que dificulta a sua interpretação e apreciação para este aspecto específico. Aparentemente, a unidade de observação para o cálculo dos agrupamentos de risco é cada uma das empresas, enquanto cada grupo CNAE é considerado como grupo homogêneo de risco, ou seja, uma categoria da variável exposição, dentro da qual se estimam os diferentes níveis de alíquota. Isto é, em cada um desses grupos CNAE ou grupo homogêneo de risco, emprega-se a análise multivariável de conglomerados (cluster analysis) para a identificação dos três grupos de risco de interesse que irão corresponder às faixas das alíquotas de contribuição.

A análise de conglomerado é amplamente utilizada em estatística para se identificar grupos de variáveis, entre um conjunto especificado de variáveis, que apresentam características comuns, tais como aquelas definidas por meio de parâmetros estatísticos. Em epidemiologia, a análise de conglomerado, como as demais análises multivariáveis, não são de uso muito comum, embora sejam populares na psicologia. A razão para tal é o ponto de partida da análise de conglomerados, que não é baseado em teoria ou no conhecimento existente (estado da arte), mas sim em achados estatísticos, que por sua vez referem-se a distâncias euclidianas que podem ser calculadas de distintas maneiras. $\mathrm{Na}$ análise, inicialmente, cada variável é considerada um único conglomerado, e em seguida as demais variáveis são agregadas baseando-se nas respectivas distâncias, formando grupos ${ }^{18}$. Para avaliar a adequação desse método ao problema em questão seria necessário um complexo trabalho de construção de simulações com parâmetros definidos, levando-se em con- 
sideração diferentes cenários, e os resultados esperados do ponto de vista da prevenção (redução da freqüência, da gravidade) e da redução dos custos, que é um dos propósitos finais do FAP. Vale ressaltar que outros procedimentos mais simples como a criação de algoritmos, aplicando-se ponderações hierarquizadas, poderiam ser empregados, com base nos próprios resultados desejados que seriam identificados a partir do exercício de simulações.

Um dos mais importantes aspectos da metodologia empregada no FAP, conforme o que se pôde apreender, é seguramente a delimitação do grupo de referência ou aquele de menor grau de risco, empregado para se estimar os riscos relativos, no caso as odds ratios ou razões de chance, que irão, subseqüentemente, traduzir os excessos de risco. Esta informação deveria estar mais claramente explicitada no texto, pois é crucial para a previsão da classificação das empresas. Além disso, como em geral a idade está em geral associada à morbidade referida, uma conseqüência possível é que os empregadores passem a selecionar seus empregados entre os mais jovens, de modo a alcançar um diferencial favorável no seu quadro de trabalhadores ativos. Um outro resultado possível é que se acentue ainda mais o chamado "efeito do trabalhador sadio", que expressa a seleção e permanência na força de trabalho dos indivíduos mais saudáveis, ou mais resistentes às próprias agressões do ambiente laboral. E, mais ainda, pode ser que ao contrário do efeito positivo esperado, de mais atenção e investimentos em medidas de prevenção de agravos e ou de promoção da saúde, intensifique-se ainda mais a sub-enumeração dos problemas de saúde, desse modo alcançando-se melhores níveis de morbidade entre os trabalhadores, conforme já mencionado. Esta questão não é fácil de ser enfrentada, considerando-se que, para não redundar no conhecido problema de fraudação de dados, seria necessária a implementação de adequados sistemas de fiscalização e re- gistro de programas de prevenção, com um apropriado mecanismo de controle social. Dada a grande dimensão do universo a ser monitorado, é claro que mudanças na política de produção de informações, em especial no que se refere a ações que levem a atitudes mais responsáveis de todas as partes interessadas, necessitam ser implementadas. Portanto, dados sobre as medidas relativas ao acompanhamento dos investimentos em proteção, prevenção, e promoção da saúde devem ser privilegiados e considerados nos aperfeiçoamentos futuros do FAP.

\section{Conclusões}

Embora o documento em anexo à Resolução 1236 apresente as bases metodológicas e teóricas da construção do FAP, há muitas lacunas, especialmente nos ensaios de aplicação com resultados concretos em diferentes cenários, que poderiam ser obtidos com simulação, para que se possa com mais firmeza e fundamentação proceder um parecer conclusivo. Todavia, com base no que foi apresentado, pode-se inferir que o FAP representa um avanço ao incluir bases científicas e empíricas para a definição das alíquotas de contribuição previdenciária para danos ocupacionais ou relacionados ao trabalho. E, especialmente, ao propor um acompanhamento contínuo e sistemático de sua metodologia, com ampla participação da sociedade, e em especial da comunidade acadêmica, componente importante para a garantia de que irá constantemente ser avaliado e ajustado. Acrescente-se também que é de grande importância a consideração de que se poderá premiar empresas, com a redução das alíquotas, quando efetivamente propiciarem melhores condições de saúde e segurança para os trabalhadores.

Vale acrescentar que uma particularidade dos agravos e doenças ocupacionais é a sua prevenção, posto que é produzido em condições manipuladas pelo homem. É óbvio que, embora a responsabilidade pela garantia e a promoção de ambientes de tra- 
balho saudáveis seja compartilhada por outras instituições do Estado, como o Ministério do Trabalho e o Ministério da Saúde, deve ser de interesse para a Previdência Social a prevenção destes problemas, modo mais lógico e racional de se reduzir a ocorrência dos AT/DT, disso resultando a redução de despesas tanto diretas quanto indiretas e, sobretudo, o impacto sobre a produtividade e o sofrimento humano.

\section{Recomendações}

- Embora a metodologia proposta represente um avanço em relação à classificação anteriormente utilizada, há disponibilidade de estratégias baseadas no conceito de carga global de doença (DALY) que vêm sendo empregadas amplamente em diversos países e poderão constituir um instigante recurso no aprimoramento do FAP;

- Empregar a razão de prevalência ou de incidência em lugar da odds ratio ou razão de chances;

- Não utilizar critérios baseados em inferência estatística, pois serão utilizados dados de toda a população;
- Apresentar maior detalhamento da definição do grupo referente e dos passos empregados na definição de agrupamento de risco de modo a deixar mais transparentes os procedimentos;

- Recomenda-se que o FAP seja continuamente avaliado em sua implementação, verificando-se em estudos conduzidos com amostras por CNAE, suas repercussões e impacto, especialmente em relação à sub-enumeração dos agravos, sejam ocupacionais ou não, o estabelecimento de medidas efetivas de prevenção dos agravos por parte das empresas, e o impacto sobre a arrecadação previdenciária;

- Garantir a participação dos trabalhadores, e da academia, em todas as etapas do desenvolvimento deste processo de monitoramento e avaliação da implantação do FAP.

\section{Agradecimentos}

Comentários do Prof. Jairnilson Paim contribuíram para o enriquecimento da última versão deste artigo.

\section{Referências}

1. Brasil Resolução No. 1236, 28 de abril de 2004. Conselho Nacional de Previdência Social. Ministério da Previdência Social.

2. Kleinbaum DG, Kupper LL, Morgestern H. Epidemiologic Research: Principles of quantitative methods. $3^{\text {rd }}$ edition, Washington: Duxbury Press; 1982.

3. Rothman K, Greenland S. Modern Epidemiology. $2^{\text {nd }}$ Ed. Philadelphia: Lippincott-Raven; 1998.

4. Dorman P. Three Preliminary Papers on the Economics of Occupational Safety and Health. International Labour Office, InFocus Programme on Safety and Health at Work and the Environment. Geneva, April 2000. (http:// www.ilo.org/public/english/protection/safework/ papers/econanal/wr_chp1.htm. Acessado em 29/01/ 2003).

5. Murray CJL, Lopez AD. The global burden of diseaseSummary. WHO; 1996.
6. Fassa AG, Fachini LA, Faria NMX. Fator Acidentário Previdenciário - uma resolução que estimula a melhoria das condições de trabalho. Conjuntura Social, 2004.

7. Beraldo OSS, Medina MG, Borba EA, Silva LP. Mortalidade por acidentes do trabalho no Brasil: Uma análise das declarações de óbito de 1979-1988. Inf Epidemiol SUS 1993; 2: 41-54.

8. Drumond JR M e cols. Avaliação da qualidade das informações de mortalidade por acidentes não especificados e eventos com intenção indeterminada. Rev Saúde Pública, São Paulo, vol. 33(3): 273-80, 1999.

9. Araújo G, Santana V, Iriart J. Sub-notificação de acidentes de trabalho e a utilização de serviços de saúde. Ciência \& Saúde Coletiva, Anais do VII Congresso Brasileiro de Saúde Coletiva, pg.22, 2003.

10. Binder MCP, Cordeiro R Sub-registro de acidentes ocupacionais no Brasil, 1997. Rev. Saúde Pública, 2003, 37:409-416. 
11. Virnig BA, McBean M Administrative data for public health surveillance and planning. Ann Review of Public Health 2001; 22:213-30.

12. Santana VS, Bouzón A, Bouzas-Filho J, Nobre L, Campos M, Silva M. Estimativa da carga e custos indiretos com os acidentes do trabalho. Universidade Federal da Bahia, Instituto de Saúde Coletiva, Programa Integrado em Saúde Ambiental e do Trabalhador, PISAT. Relatório de Pesquisa apresentado ao Ministério da Saúde, Coordenação de Saúde do Trabalhador. Salvador; junho de 2004.

13. Hill BA. The environment and disease: association or causation? Section of Occupational Medicine 1965; 295300 .

14. Morgestern H. Introductory texts in Epidemiology. University of California at Los Angeles, UCLA; 1990.
15. Cornfield, J. 1951. A method of estimating comparative rates from clinical data: applications to cancer of lungs, breast and cervix. JNCI 11:1269-75.

16. Durbin D. Workplace injuries and the role of insurance: claims costs, outcomes and incentives. Clin Orthopaed Related Dis. 1997; 1(336):18-32.

17. Boden LI, Biddle EA, Spieler EA. Social and economic impacts of workplace illness and injury: current and future directions for research. Amer J Ind Med 2001; 40: 398-402.

18. CNPS. Resolução No. 1.236, de 28 de abril de 2004. Ministério da Previdência Social.

19. Marriott FHC. The interpretation of multiple observations. London: Academic Press; 1995.

Recebido em: 18/01/05

Versão reformulada reapresentada em: 10/11/05

Aprovado em: 14/11/05 